\title{
Research on Innovation of English Teaching in Colleges_— Teaching Methods
}

\author{
Xiangying Tu${ }^{1}$, Yesheng Sun ${ }^{2}$ \\ ${ }^{1}$ Jiangxi Institute of Applied Science and Technology, Nanchang, Jiangxi, 330100 \\ ${ }^{2}$ Jiangxi Modern Polytechnic College, Nanchang, Jiangxi, 330095
}

Keywords: teaching method; English teaching; innovation teaching

\begin{abstract}
With the globalization of the economy and trade and the development of the market economy, foreign languages become the basic criteria for talent selection. The international language communication ability is one of the capabilities that college students should possess when meeting the various challenges brought about by the information age and economic globalization. How to improve the level of English teaching in colleges and universities, carry out innovative teaching work, and cultivate the overall quality of college students have become an important issue in current College English teaching. This paper starts from the actual situation of College English teaching, expounds the connotation of College English teaching innovation from various aspects such as teaching content, teaching model, and teaching thinking, grasps the theoretical basis and practical application of College English teaching innovation in today's quality education.
\end{abstract}

\section{Introduction}

Innovation education aims to cultivate the innovative awareness and innovative thinking of college students, and enhance the ability of students to practice and solve problems. The ultimate goal is to cultivate innovative talents and applications. The traditional education adopts the infusion teaching mode. The teacher's lecture is not proportional to the student's internalization, and the purpose of education is only for exam-oriented education. Since the implementation of quality education, it has still been affected by the traditional education model. There are some problems that restrict the development of education. Through exploration and practice, it has been proved that the traditional education model has gradually revealed limitations and deficiencies. Affected and restricted by the traditional education model, the teacher's education concept is backward, lacks corresponding innovation ideas, students lack interest and enthusiasm for learning, and lack active participation. The ability to independently solve problems is not conducive to improving the quality of teachers and the efficiency of student learning. It is not conducive to improving the quality and efficiency of teaching. In today's rapid social development, social needs are innovative talents adapted to social development. College English teaching must also advance with the times and conform to the trend of the times. On the one hand, it is necessary to draw on and learn from the experience and lessons of previous English teaching. On the one hand, it is necessary to update the teaching philosophy, implement innovative education in English teaching, and cultivate innovation that conforms to the trend of the times. Talents and applied talents.

\section{Connotation of College English Teaching Innovation}

English teaching innovation refers to creative teaching of English in accordance with the requirements of the syllabus, respecting teaching rules, focusing on personality shaping, and cultivating a comprehensive quality of innovative teaching process. From the view of educational theory, English teaching innovation refers to the systematic and flexible use of English language as a teaching medium in the process of education. Students are trained to form a capacity based on the overall knowledge. Innovation in English teaching essentially includes the following meanings:

College English teaching is different from traditional English higher education. English teaching in higher vocational colleges focuses more on training students' listening, speaking, reading, writing and other application abilities. In listening and speaking, pay attention to the practical significance 
of vocabulary, strengthen conversation and communication training, and focus on shorthand and phonetic training in reading and writing.

The outline of English teaching in higher vocational colleges is relatively general, but the basic education teaching idea is still based on "cultivation of people and ability-based".

Especially in the selection of teaching methods, we must "funny, stimulating, affectionate, and interested”, and should be consistent with students' psychological needs and knowledge levels.

English teaching in higher vocational colleges is aimed at shaping the students' noble personality and cultivating the ability to use the language.

\section{Status Quo of College English Teaching}

English is a very practical basic course, but the English teaching ideas of higher vocational colleges have always been relatively old, teaching models are relatively single, teaching is the core of teaching, and teachers are the absolute dominant position in the classroom. Most students can only passively accept knowledge. This traditional teaching model is often used to teach language as knowledge. This is contrary to the objective law of learning a second language. Most of the students' English learning can only be in the stage of memory and understanding. Relatively poor. This has caused many students to spend a lot of time learning English, but the effect they receive is very limited. There are many reasons for this situation. The following analysis will be combined with the teaching practice.

As the enrollment scale of universities and colleges continues to expand, the quality of students in some higher vocational schools deteriorates. Many students have a poor English foundation and their learning ability needs to be improved. This directly led to a variety of problems in the style of study. Students' gaps in the level of uneven English have also increased, adding to the difficulty of teaching English. In addition, in the teaching of English courses, teachers often only pay attention to the teaching of knowledge, but lack attention to the cultivation of students' ability. As a result, the teacher speaks more and the students practice less. The students can only passively and passively. Taking notes, the subjective initiative of oneself is not well played, and the efficiency of classroom teaching is naturally not high.

In higher vocational colleges, although the Ministry of Education did not link the degree with the English exams at the 4th and 6th levels, during the course of the implementation, some schools still passed the exams to award students various aspects. This virtually makes the teacher's teaching work biased towards coping with the exam, and the student's learning is also aimed at passing the 4th and 6th level. This single English learning evaluation model is not conducive to the overall development of the students' overall quality, making some of the more practical Oral English is not well developed and promoted. The effect of English learning is not good.

\section{Application of Innovative Education in College English Teaching}

The content of college English textbooks covers astronomy, geography and humanism. With professional knowledge, it also provides foundation and guarantee for college students to form values. College English guides and promotes the understanding and mastery of the differences between Chinese and Western cultures through English textbooks. It helps to open up students' horizons and form values and worldviews that are consistent with the times. In the English class of Colleges, we should fully explore the content of English textbooks, enhance students' innovative ability and practical ability, and at the same time cultivate the scientific and reasonable values of college students. First, English teachers in institutions of higher learning should enhance their professional quality, change their concepts of teaching, use creative elements from English textbooks, and develop the innovative spirit and practical ability of college students step by step. Second, English teachers in institutions of higher learning To combine traditional domestic culture, using English textbooks to enable college students to understand the Western cultural background, open up the horizons of college students, and allow college students to form scientific and reasonable values and world views in the emotional experience, to lay the foundation and provide 
guarantees for college students to form innovative thinking; Thirdly, English teachers in institutions of higher learning should conduct in-depth excavation of English textbooks, guide students to solve problems independently, develop innovative thinking and independent problem-solving abilities for college students, and enable college students to think and explore from different perspectives. To achieve an effect of analogy and analogy.

English teachers in institutions of higher learning can search, download and use current-time related and life-related videos and images through the Internet, use modern multimedia technology to play videos, images and sounds for students, and use intuitive teaching principles to stimulate student learning. Interest, in turn, cultivates students' initiative and enthusiasm for learning, so that students are willing to participate in the learning process; At the same time, college English teachers can also ask questions according to the video content to guide students to learn independently, think independently, and explore independently. Making use of students' personal involvement and experience to transform students' passive acceptance of knowledge into active learning and exploration of knowledge helps arouse students' enthusiasm and interest in learning English, and also contributes to classroom efficiency. The training of college students' interest in learning and motivation for learning depends on the joint efforts of schools, teachers, families, and individuals. The school organizes English speaking competitions, English writing, English Blackboard newspapers, English Corner and other activities to create a good English learning atmosphere for students. Students are encouraged to learn English and stimulate English learning by following the campus spiritual culture. Interest and learning motivation; Teachers should give full play to the leading role of teaching in the teaching process, combining students' indirect experience and direct experience to reflect the main role of students in learning, and take student-oriented teaching activities as their focus. The student's personal experience, in turn, enables students to generate interest and motivation for learning English through personal experience. Schools and families must work together to create a good English learning environment for students and allow students to learn English in a subtle manner so that students can develop English learning interest. Individual students must also make full use of their subjective initiative to gradually cultivate their interest in learning English through English movies, English songs, and so on.

Innovative thinking is the foundation and prerequisite for innovation ability. It is a concentrated expression of advanced human thinking, and divergent thinking plays a leading role in innovative thinking. Innovative thinking is the intrinsic motive force of creative ability and the prerequisite and guarantee for cultivating creative ability. Innovative thinking, with its own initiative, originality and divergent thinking, abandons the limitations and deficiencies of conventional thinking, with new and Creativity and thinking to analyze and solve various problems. The divergent thinking in innovative thinking has the characteristics of flexibility, uniqueness and fluency. The thinking space is wider and the field of vision is more open-minded. Its way of thinking is not limited by time and space. In English teaching activities in institutions of higher learning, teachers can use physical models, videos, pictures, videos, and PPT courseware to display and impart knowledge to college students so that college students can intuitively recognize what they have learned. And the content will help college students accumulate rich knowledge, stimulate students' interest in learning and motivation, allow college students to actively participate in teaching activities, and enhance the thinking intensity and thinking space of college students.

The goal of English teaching in institutions of higher learning is to promote the ability of language communication and language learning of college students through English learning. Therefore, in English teaching in institutions of higher learning, we should abandon the limitations of traditional textbooks. We should not only focus on the accumulation of vocabulary and the application of grammar, but should focus on the communication and practical application of spoken English. In English language teaching activities, students should not be indoctrinated and injected with knowledge in the university, but should use the knowledge and related cases in English textbooks flexibly. First, when conducting vocabulary teaching, you can compose words or derive other meanings from the boring vocabulary. The contents of the teaching materials are transformed into easy-to-understand and understandable knowledge in Colleges. This helps college students 
master vocabulary and reflect vocabulary. Lively use. Secondly, in English teaching activities in institutions of higher learning, students' knowledge can be consolidated through repetitions of texts and scenarios. At the same time, it is also a teaching evaluation of teaching effectiveness and student learning. Third, English teaching in universities and colleges. In the activity, English knowledge and concepts can be combined with examples in daily life to link the knowledge structure of college students with real life, and to promote the understanding and mastery of English knowledge among college students.

\section{Conclusion}

The English teaching of college students should not be limited to the mastery of English knowledge, but should focus on the cultivation and promotion of college students' language learning ability. At the same time, it is necessary to focus on the cultivation of ability and practical ability in English teaching activities. The essence of innovation education is to cultivate students' innovative consciousness and innovative thinking, which is conducive to the overall development of college students, and is highly consistent with the goals of quality education and the concept of new curriculum reform. Therefore, in college English teaching activities, creative education should be integrated into daily teaching activities, combining the students' main role with the teacher's leading role, and combining students' indirect experience with direct experience.

\section{References}

[1] Zhang Wenjun. The application of innovative teaching model in college English teaching [J]. Journal of Mudanjiang Institute of Education, 2013(3): 122 - 123.

[2] Ge Yan. On the strategy of implementing innovative education in college English teaching [J]. Journal of Huainan Vocational and Technical College, 2016, 16(1): 73 - 75.

[3] Cao Ruiming. Innovative education and the cultivation of English high-quality personnel [J]. Journal of Luoyang University, 2004, 19(1): 114 - 117.

[4] Qian Yadong, Ruan Guoning, Li Xiangshuo, Dong Baoli, Gu Xinjian. Network-based instrument and equipment sharing research [J]. Computer Integrated Manufacturing System, 2005, (8): 1169-1173.

[5] Xia Wei, Zhang Yipin. Discussion on Laboratory Resource Management in Higher Vocational Colleges [J]. Journal of Zhejiang Water Conservancy and Hydropower College, 2011, (9): 85-87. 